\title{
The study of crystal and magnetic properties of $\mathrm{MnNi}_{0.85} \mathrm{Fe}_{0.15} \mathrm{Ge}$
}

\author{
Mieczysław Budzyński, \\ Viktor I. Valkov, \\ Alexei V. Golovchan, \\ Viktor I. Mitsiuk, \\ Alexandr P. Sivachenko, \\ Zbigniew Surowiec, \\ Tamara M. Tkachenka
}

\begin{abstract}
Magnetic and Mössbauer measurements were performed for $\mathrm{MnNi}_{0.85} \mathrm{Fe}_{0.15} \mathrm{Ge}$. The Mössbauer data indicate that $\mathrm{Fe}$ atoms in $\mathrm{MnNi}_{0.85} \mathrm{Fe}_{0.15} \mathrm{Ge}$ are randomly distributed over two types of metal sites in hexagonal structure. At $77 \mathrm{~K}$, the hyperfine magnetic fields at Fe located in different crystal sites have similar values of about 12.7 and 12.3 T. The random site distribution of the iron atoms in the non-magnetic hexagonal phase at high temperatures is confirmed by the theoretical calculations in fully relativistic Korringa-Kohn-Rostoker (KKR) method.
\end{abstract}

Key words: Mössbauer effect • magnetic interaction • hexagonal structure

M. Budzyński, Z. Surowiec

Institute of Physics,

M. Curie-Skłodowska University,

1 M. Curie-Skłodowskiej Sq., 20-031 Lublin, Poland

V. I. Valkov, A. V. Golovchan, A. P. Sivachenko

Donetsk Institute for Physics and Engineering,

72 R. Luxemburg Str., 83114 Donetsk, Ukraine

V. I. Mitsiuk, T. M. Tkachenka ${ }^{\bowtie}$

Scientific-Practical Materials Research Center

of National Academy of Sciences of Belarus,

19 P. Brovky Str., 220072 Minsk, Belarus,

Tel.: +375 17284 1301, Fax: +375 17284 1558,

E-mail:1ttt@physics.by

Received: 18 June 2014

Accepted: 4 November 2014

\section{Introduction}

The effect of magnetostructural coupling in systems with martensite-like phase transitions plays an important role in magnetoresponsive effects, such as magnetoresistance, magnetocaloric effect, etc. The materials with stable magnetostructural coupling between the structural and the magnetic transition over a broad-temperature region from 70 to $350 \mathrm{~K}$ in combination with tunable magnetoresponsive effects are extremely interesting for a practical use. Recently, the possibility to obtain such a combination of properties has been shown for MnNiGe:Fe alloys [1,2].

The purpose of the work was the magnetometric and Mössbauer studies of structural and magnetic characteristics of two different heat-treated $\mathrm{MnNi}_{0.85} \mathrm{Fe}_{0.15} \mathrm{Ge}$ alloys.

\section{Results and discussion}

The $\mathrm{MnNi}_{0.85} \mathrm{Fe}_{0.15} \mathrm{Ge}$ samples were produced by melt spinning in Ar atmosphere at a wheel linear speed of $20 \mathrm{~m} \cdot \mathrm{s}^{-1}$ from as-cast pellets of nominal composition $\mathrm{MnNi}_{0.85} \mathrm{Fe}_{0.15} \mathrm{Ge}$ previously obtained by arc melting from highly pure elements. Then the samples are (1) quenched and (2) quenched + annealed $(6 \mathrm{~h}$, $850^{\circ} \mathrm{C}$, in vacuum). X-ray powder analysis at room temperature shows that all samples have a hexagonal $\mathrm{Ni}_{2}$ In-type crystal structure (space group $P 6_{3} / m m c$ ). 
Table 1. Magnetic characteristics of $\mathrm{MnNi}_{0.85} \mathrm{Fe}_{0.15} \mathrm{Ge}$

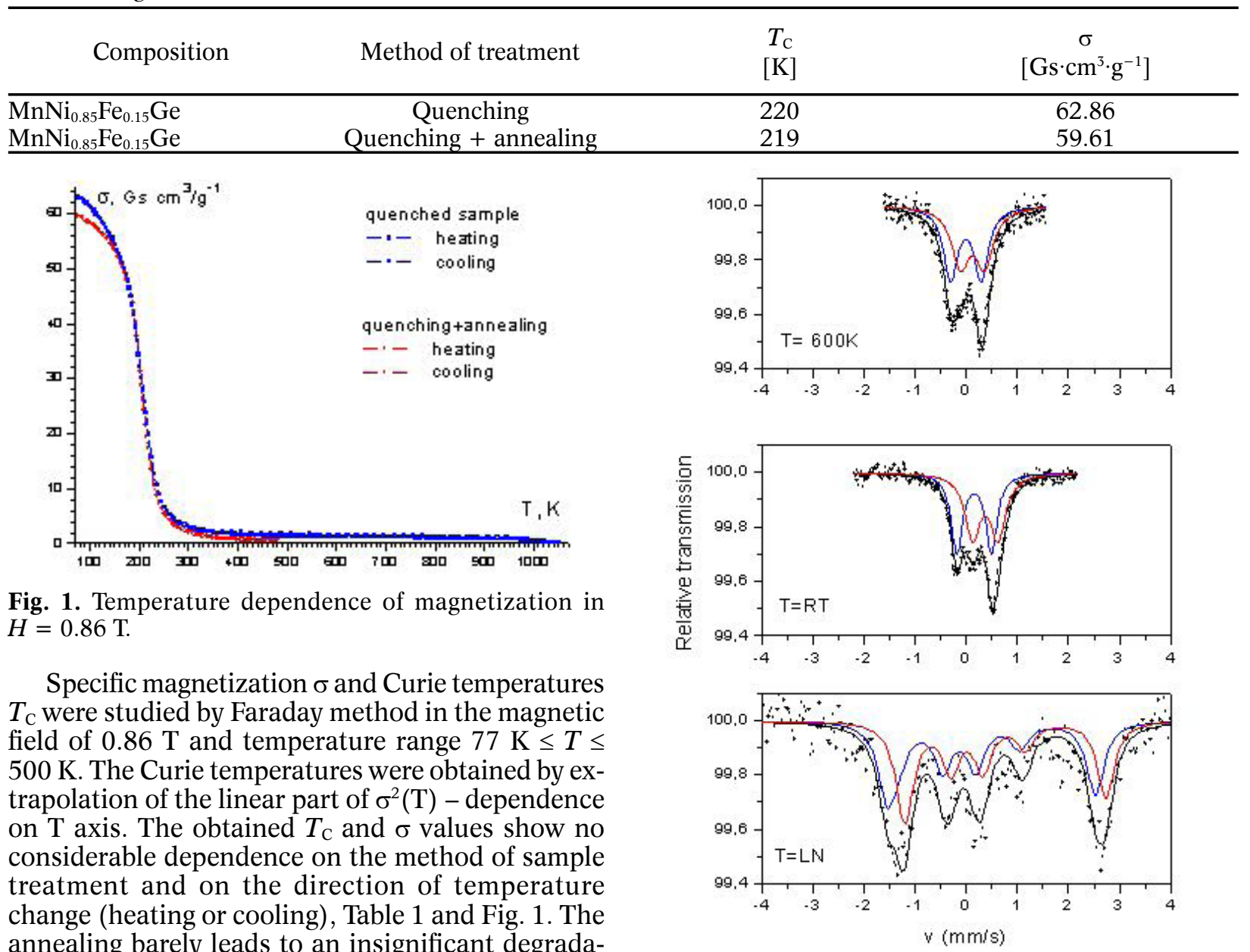
annealing barely leads to an insignificant degradation of magnet characteristics.

Mössbauer experiment was made in usual transmission geometry and constant acceleration regime. ${ }^{57} \mathrm{Fe} / \mathrm{Rh}$ was used as a resonance source, the sample temperatures were $77 \mathrm{~K} \leq T \leq 600 \mathrm{~K}$. The Mössbauer spectra are shown in Fig. 2, the spectra fitting results are given in Table 2 .

It has been shown that the MnFeGe alloy crystallizes in the $\mathrm{Ni}_{2}$ In-type structure (Fig. 3a) in the whole temperature range [3]. Magnetic moments are localized on both $\mathrm{Mn}$ and Fe sites. Neutron diffraction study of a powdered $\mathrm{Fe}_{1.0} \mathrm{Mn}_{0.95} \mathrm{Ge}$ sample below $240 \mathrm{~K}$ has shown that the Mn magnetic moments are ordered in antiferromagnetic way whereas the Fe moments are ordered ferromagnetically [4]. Stoichiometric MnNiGe alloy at room temperature has the orthorhombic (TiNiSi-type) crystal structure

Fig. 2. ${ }^{57} \mathrm{Fe}$ Mössbauer spectra of $\mathrm{MnNi}_{0.85} \mathrm{Fe}_{0.15} \mathrm{Ge}$ (quenched) at different temperatures.

(Fig. 3b) (space group $P_{n m a}$ ) and shows a spiral antiferromagnet (AFM) state below the Neel temperature $T_{\mathrm{N}}=$ $346 \mathrm{~K}$. At about $470 \mathrm{~K}$, it undergoes a crystallographic structural transition from the low-temperature orthorhombic phase to the high-temperature hexagonal phase [5]. In the case of Fe-doped MnNiGe alloys, the $\mathrm{Ni}_{2}$ In-type instead of the TiNiSi-type structure is observed at room temperature (RT), suggesting a remarkable reduction of transconformation temperature $\left(T_{t}\right)$. It was reported that the $\mathrm{Ni}$ atoms in $\mathrm{MnNiGe}$ alloy are non-magnetic, leaving the moments of $\mathrm{Mn}$ atoms aligning in the spiral AFM ordering [6].

In [7] the ${ }^{57} \mathrm{Fe}$ Mössbauer spectrum of MnFeGe ternary alloy at room temperature $(290 \mathrm{~K})$ was fitted

Table 2. ${ }^{57} \mathrm{Fe}$ Mössbauer parameters of $\mathrm{MnNi}_{0.85} \mathrm{Fe}_{0.15} \mathrm{Ge}$ (quenched) spectra

\begin{tabular}{ccccccccccc}
\hline & \multicolumn{1}{c}{ 1 subspectrum } \\
\cline { 2 - 12 }$[\mathrm{K}]$ & $\begin{array}{c}\mathrm{IS}_{1} \\
{[\mathrm{~mm} / \mathrm{s}]}\end{array}$ & $\begin{array}{c}\mathrm{QS}_{1} \\
{[\mathrm{~mm} / \mathrm{s}]}\end{array}$ & $\begin{array}{c}H_{1} \\
{[\mathrm{~T}]}\end{array}$ & $\begin{array}{c}\mathrm{G}_{1} \\
{[\mathrm{~mm} / \mathrm{s}]}\end{array}$ & $\mathrm{C}_{1}$ & $\begin{array}{c}\mathrm{IS}_{2} \\
{[\mathrm{~mm} / \mathrm{s}]}\end{array}$ & $\begin{array}{c}\mathrm{QS}_{2} \\
{[\mathrm{~mm} / \mathrm{s}]}\end{array}$ & $\begin{array}{c}H_{2} \\
{[\mathrm{~T}]}\end{array}$ & $\begin{array}{c}\mathrm{G}_{2} \\
{[\mathrm{~mm} / \mathrm{s}]}\end{array}$ & $\mathrm{C}_{2}$ \\
\hline 77 & 0.264 & -0.312 & 12.70 & 0.210 & 0.479 & 0.470 & -0.370 & 12.30 & 0.200 & 0.521 \\
290 & 0.241 & 0.679 & - & 0.135 & 0.479 & 0.462 & 0.498 & - & 0.183 & 0.521 \\
500 & 0.095 & 0.300 & - & 0.148 & 0.479 & 0.321 & 0.261 & - & 0.158 & 0.521 \\
600 & 0.077 & 0.300 & - & 0.168 & 0.479 & 0.206 & 0.236 & - & 0.200 & 0.521 \\
\hline
\end{tabular}

IS - isomer shift value relative to metallic Fe (error \pm 0.005$)$. QS - quadrupole splitting value (error \pm 0.008 ). $H$ - hyperfine magnetic field at $\mathrm{Fe}$ atom (error \pm 0.05$)$. $\mathrm{G}$ - line width (error \pm 0.005$)$. $\mathrm{C}$ - relative contribution of the subspectrum area to the total spectrum area. 
a

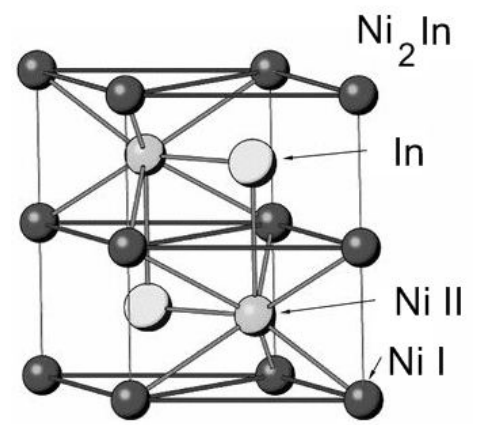

Fig. 3. Crystal structures types: (a) $\mathrm{Ni}_{2} \mathrm{In}$, (b) TiNiSi.

in one doublet model with the doublet parameters: quadrupole splitting $(\mathrm{QS})=0.70 \mathrm{~mm} / \mathrm{s}$ and isomer shift (IS) $=0.30 \mathrm{~mm} / \mathrm{s}$. However, elsewhere [3] the Mössbauer spectra of MnFeGe and $\mathrm{NiFeGe}$ were fitted in a two subspectra model. In the present work, each spectrum of $\mathrm{MnNi}_{0.85} \mathrm{Fe}_{0.15} \mathrm{Ge}$ at each temperature was presented as superposition of two subspectra.

In the paramagnetic region, the $\mathrm{MnNi}_{0.85} \mathrm{Fe}_{0.15} \mathrm{Ge}$ spectra were presented by superposition of two doublets as there are two different types of sites for the metal atoms in the hexagonal structure - with octahedral and trigonal-bipyramidal anionic environment, Fig. 3a. So the presence of two doublets in each Mössbauer spectrum corresponds to the essentialities of crystal structure. The parameters of one doublet are close to those of the only doublet in [7]. A conspicuous experimental fact is that the IS and QS values in paramagnetic $\mathrm{MnNi}_{0.85} \mathrm{Fe}_{0.15} \mathrm{Ge}$ state at room temperature significantly differ from those at 500 and $600 \mathrm{~K}$ (Table 2).

The spectrum of $\mathrm{MnNi}_{0.85} \mathrm{Fe}_{0.15} \mathrm{Ge}$ (quenched) at $T=77 \mathrm{~K}$ is magnetically split and it also fitted in a two subspectra model as there are two types of metal sites in the inherent orthorhombic structure. There are two magnet sextets in the spectrum with similar values of hyperfine magnetic fields at $\mathrm{Fe}$ of approximately $12.7 \mathrm{~T}$ and $12.3 \mathrm{~T}$ and broadened line width. The orthorhombic structure at $T=77 \mathrm{~K}$ is not ideal and the electric field gradient axis is not uniquely oriented with respect to the magnetization direction. In such cases, the occurrence of the complex set of Zeeman patterns attributed to one sublattice can be observed [8] or it could give rise to appreciable line width broadening.

It is accepted [3,9] that the (1) Mn and (2) $\mathrm{Ni}$ or $\mathrm{Fe}$ atoms are located in different structural positions in MnNiGe or MnFeGe three-component systems. Namely, Mn atoms are located in MeI, and $\mathrm{Fe}$ or $\mathrm{Ni}-$ in MeII. But the presence of two subspectra in each Mössbauer spectrum testifies to the substitution of $\mathrm{Fe}$ atoms for either $\mathrm{Mn}$ or $\mathrm{Ni}$ in $\mathrm{MnNi}_{0.85} \mathrm{Fe}_{0.15} \mathrm{Ge}$. The relative contributions of corresponding subspectra to the total spectrum are almost equal. So the important conclusion is that the $\mathrm{Fe}$ atoms in $\mathrm{MnNi}_{0.85} \mathrm{Fe}_{0.15} \mathrm{Ge}$ at small concentration (notably 15 at.\%) are randomly distributed over the two types of metal sites in the orthorhombic or hexagonal structure. At $77 \mathrm{~K}$, the hyperfine magnetic fields at $\mathrm{Fe}$ atoms located in different metal sites in $\mathrm{MnNi}_{0.85} \mathrm{Fe}_{0.15} \mathrm{Ge}$ have similar values. b

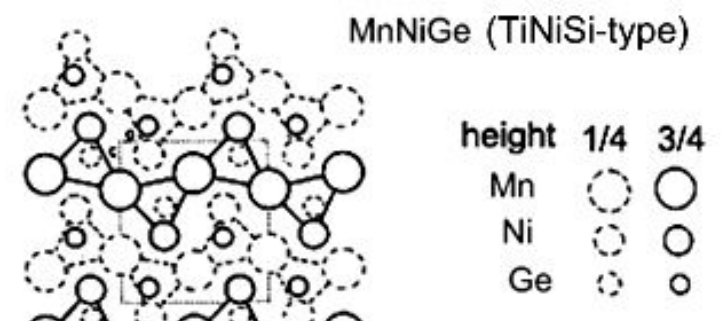

The experimental fact of similarity of magnetic field values at $\mathrm{Fe}$ in different crystal positions does not correspond to the calculated results obtained in the work. The hyperfine field values have been calculated by the fully relativistic Korringa - Kohn- Rostoker (KKR) method [10] in linear discrimination analysis Vosko-Wilk-Nusair method (LDA $($ VWN ) [11] and generalized gradient approximation Perdew-Burke-Ernzerhof method (GGA (PBE) ) [12] approximations for exchange-correlation energy and atomic sphere approximation for crystal potential. According to the calculations in both LDA and GGA approximations (Table 3), the iron atoms in the non-magnetic hexagonal phase at high temperatures are almost randomly distributed over positions of $\mathrm{Ni}$ and $\mathrm{Mn}$.

$$
\begin{gathered}
\Delta E_{\mathrm{NM}, \mathrm{hex}}=E\left[\left(\mathrm{Mn}_{0.99} \mathrm{Fe}_{0.01}\right)_{2 \mathrm{a}}\left(\mathrm{Ni}_{0.85} \mathrm{Fe}_{0.14} \mathrm{Mn}_{0.01}\right)_{2 \mathrm{c}} \mathrm{Ge}\right]- \\
\quad-\left[\left(\mathrm{Mn}_{0.86} \mathrm{Fe}_{0.14}\right)_{2 \mathrm{a}}\left(\mathrm{Ni}_{0.85} \mathrm{Fe}_{0.01} \mathrm{Mn}_{0.14}\right)_{2 \mathrm{c}} \mathrm{Ge}\right] \\
=-132 \text { Cal/f.u. (Calories per formula unit). }
\end{gathered}
$$

In the ferromagnetic state, the energy difference between these configurations in the hexagonal phase increases up to $\Delta E_{\mathrm{FM} \text {,hex }}=-623 \mathrm{Cal} / \mathrm{f}$.u., and in the orthorhombic phase - up to $\Delta E_{\mathrm{FM}, \text { orth }}=$ $-846 \mathrm{Cal} / \mathrm{f}$.u. Therefore, quenching can freeze the 'non-equilibrium' distribution of $\mathrm{Fe}$ atoms on $\mathrm{Ni}$ and Mn sublattices, as well as part of the "non-equilibrium' of the orthorombic phase. The comparison of calculated hyperfine magnetic fields (Table 3) with experimental values $(12.7 \mathrm{~T}$ and $12.3 \mathrm{~T})$ shows that the best agreement with the experimental data would be if iron atoms are in the Mn sublattice in the alloy with orthorhombic ferromagnetic (FM) phase. In this case, $H_{\mathrm{hf}}=13.5 \mathrm{~T}$, but in fact, the Fe atoms have them in Ni positions of this structure as well.

\section{Conclusions}

The Mössbauer data indicate that $\mathrm{Fe}$ atoms in $\mathrm{MnNi}_{0.85} \mathrm{Fe}_{0.15} \mathrm{Ge}$ are randomly distributed over two types of metal sites in the orthorhombic or hexagonal structure. At $77 \mathrm{~K}$, the hyperfine magnetic fields at Fe located in different crystal sites have similar values of about 12.7 and $12.3 \mathrm{~T}$. The theoretical calculations also show that the iron atoms in the non-magnetic hexagonal phase at high temperatures are almost randomly distributed over positions of $\mathrm{Ni}$ and $\mathrm{Mn}$. The sample quenching can freeze the 'non-equilibrium' distribution of Fe atoms on $\mathrm{Ni}$ and $\mathrm{Mn}$ 
Table 3. Hyperfine magnetic fields calculated with SPRKKR code [10]

\begin{tabular}{|c|c|c|c|c|c|c|c|c|}
\hline Alloy & $M\left(\mathrm{Mn}_{\mathrm{I}}\right)$ & $M\left(\mathrm{Fe}_{\mathrm{I}}\right)$ & $H_{\mathrm{hfl}}, \mathrm{T}$ & $M\left(\mathrm{Mn}_{\mathrm{II}}\right)$ & $M\left(\mathrm{Fe}_{\mathrm{II}}\right)$ & $H_{\text {hfII }}$ & $M_{\text {f.u. }}$ & $E_{\text {tot }}$, Ry/f.u. \\
\hline \multicolumn{9}{|c|}{ Hexagonal $\mathrm{Ni}_{2}$ In-type structure, LDA approximation, non-magnetic } \\
\hline$\left(\mathrm{Mn}_{0.86} \mathrm{Fe}_{0.14}\right)_{\mathrm{I}}\left(\mathrm{Ni}_{0.85} \mathrm{Fe}_{0.01} \mathrm{Mn}_{0.14}\right)_{\mathrm{II}} \mathrm{Ge}$ & - & - & - & - & - & - & - & -9468.06075 \\
\hline$\left(\mathrm{Mn}_{0.99} \mathrm{Fe}_{0.01}\right)_{\mathrm{I}}\left(\mathrm{Ni}_{0.85} \mathrm{Fe}_{0.14} \mathrm{Mn}_{0.01}\right)_{\mathrm{II}} \mathrm{Ge}$ & - & - & - & - & - & - & - & -9468.06159 \\
\hline \multicolumn{9}{|c|}{ Hexagonal $\mathrm{Ni}_{2}$ In-type structure, GGA approximation, non-magnetic } \\
\hline$\left(\mathrm{Mn}_{0.86} \mathrm{Fe}_{0.14}\right)_{\mathrm{I}}\left(\mathrm{Ni}_{0.85} \mathrm{Fe}_{0.01} \mathrm{Mn}_{0.14}\right)_{\mathrm{II}} \mathrm{Ge}$ & - & - & - & - & - & - & - & -9482.84201 \\
\hline$\left(\mathrm{Mn}_{0.95} \mathrm{Fe}_{0.05}\right)_{\mathrm{I}}\left(\mathrm{Ni}_{0.85} \mathrm{Fe}_{0.10} \mathrm{Mn}_{0.05}\right)_{\mathrm{II}} \mathrm{Ge}$ & - & - & - & - & - & - & - & -9482.84255 \\
\hline \multicolumn{9}{|c|}{ Hexagonal $\mathrm{Ni}_{2}$ In-type structure, LDA approximation, ferromagnetic } \\
\hline$\left(\mathrm{Mn}_{0.86} \mathrm{Fe}_{0.14}\right)_{\mathrm{I}}\left(\mathrm{Ni}_{0.85} \mathrm{Fe}_{0.01} \mathrm{Mn}_{0.14}\right)_{\mathrm{II}} \mathrm{Ge}$ & 2.71 & 2.26 & -14.4 & 0.91 & 1.19 & -15.5 & 2.78 & -9468.08958 \\
\hline$\left(\mathrm{Mn}_{0.99} \mathrm{Fe}_{0.01}\right)_{\mathrm{I}}\left(\mathrm{Ni}_{0.85} \mathrm{Fe}_{0.14} \mathrm{Mn}_{0.01}\right)_{\mathrm{II}} \mathrm{Ge}$ & 2.71 & 2.27 & -14.5 & 0.26 & 1.00 & -15.8 & 2.83 & -9468.09353 \\
\hline \multicolumn{9}{|c|}{ Hexagonal $\mathrm{Ni}_{2}$ In-type structure, GGA approximation, ferromagnetic } \\
\hline$\left(\mathrm{Mn}_{0.86} \mathrm{Fe}_{0.14}\right)_{\mathrm{I}}\left(\mathrm{Ni}_{0.85} \mathrm{Fe}_{0.01} \mathrm{Mn}_{0.14}\right)_{\mathrm{II}} \mathrm{Ge}$ & 2.98 & 2.44 & -17.1 & 1.58 & 1.42 & -17.0 & 3.12 & -9482.87981 \\
\hline$\left(\mathrm{Mn}_{0.95} \mathrm{Fe}_{0.05}\right)_{\mathrm{I}}\left(\mathrm{Ni}_{0.85} \mathrm{Fe}_{0.10} \mathrm{Mn}_{0.05}\right)_{\mathrm{II}} \mathrm{Ge}$ & 3.00 & 2.47 & -17.2 & 1.15 & 1.33 & -17.6 & 3.14 & -9482.88268 \\
\hline \multicolumn{9}{|c|}{ Orthorhombic TiNiSi-type structure, LDA approximation, ferromagnetic } \\
\hline$\left(\mathrm{Mn}_{0.86} \mathrm{Fe}_{0.14}\right)_{\mathrm{I}}\left(\mathrm{Ni}_{0.85} \mathrm{Fe}_{0.01} \mathrm{Mn}_{0.14}\right)_{\mathrm{II}} \mathrm{Ge}$ & 2.84 & 2.24 & -13.5 & 2.22 & 1.75 & -20.5 & 3.10 & -9468.19401 \\
\hline$\left(\mathrm{Mn}_{0.99} \mathrm{Fe}_{0.01}\right)_{\mathrm{I}}\left(\mathrm{Ni}_{0.85} \mathrm{Fe}_{0.14} \mathrm{Mn}_{0.01}\right)_{\mathrm{II}} \mathrm{Ge}$ & 2.84 & 2.25 & -14.1 & 2.21 & 1.73 & -21.7 & 3.10 & -9468.19938 \\
\hline \multicolumn{9}{|c|}{ Orthorhombic TiNiSi-type structure, GGA approximation, ferromagnetic } \\
\hline$\left(\mathrm{Mn}_{0.86} \mathrm{Fe}_{0.14}\right)_{\mathrm{I}}\left(\mathrm{Ni}_{0.85} \mathrm{Fe}_{0.01} \mathrm{Mn}_{0.14}\right)_{\mathrm{II}} \mathrm{Ge}$ & 2.97 & 2.33 & -14.7 & 2.37 & 1.82 & -22.9 & 3.18 & -9482.98647 \\
\hline$\left(\mathrm{Mn}_{0.95} \mathrm{Fe}_{0.05}\right)_{\mathrm{I}}\left(\mathrm{Ni}_{0.85} \mathrm{Fe}_{0.10} \mathrm{Mn}_{0.05}\right)_{\mathrm{II}} \mathrm{Ge}$ & 2.97 & 2.33 & -15.1 & 2.36 & 1.81 & -23.8 & 3.17 & -9482.99038 \\
\hline
\end{tabular}

sublattices in $\mathrm{MnNi}_{0.85} \mathrm{Fe}_{0.15} \mathrm{Ge}$ as well as the part of the 'non-equilibrium' hexagonal phase.

Acknowledgments. The work was partly supported by Grant No. T13K-003 (Belarusian Republican Foundation for Fundamental Research) and Grant No. $\Phi 54.1 / 003$ (Ukrainian Republican Foundation for Fundamental Research).

\section{References}

1. Liu, E., Wang, W., Feng, L., Zhu, W., Li, G., Chen, J., Zhang, H., Wu, G., Jiang, C., Xu, H., \& de Boer, F. (2012). Stable magnetostructural coupling with tunable magnetoresponsive effects in hexagonal ferromagnets. Nat. Commun., 3, 873. DOI: 10.1038/ ncomms1868.

2. Chen, L., Hu, F. X., Wang, J., Bao, L. F., Sun, J. R., Shen, B. G., Yin, J. H., \& Pan, L. Q. (2012). Magnetoresistance and magnetocaloric properties involving strong metamagnetic behavior in Fe-doped $\mathrm{Ni}_{45}\left(\mathrm{Co}_{1-\mathrm{x}} \mathrm{Fe}_{\mathrm{x}}\right)_{5} \mathrm{Mn}_{36.6} \mathrm{In}_{13.4}$ alloys. Appl. Phys. Lett., 101, 012401-1-012401-4. DOI: http:// dx.doi.org/10.1063/1.4732525.

3. Szytula, A., Pędziwiatr, A. T., Tomkowicz, Z., \& Bazela, W. (1981). Crystal and magnetic structure of CoMnGe, CoFeGe, FeMnGe and NiFeGe. J. Magn. Magn. Mater., 25, 176-186.

4. Bhargava, S. C., \& Iyengar, P. K. (1974). Hyperfine interactions of iron in ternary alloys with $\mathrm{B}_{2}$ type structures. Framana, 2(3), 126-137. DOI: http:// repository.ias.ac.in/12443/1/316.pdf.
5. Zhang, C. L., Wang, D. H., Zhang, C. L., Wang, D. H., Chen, J., Wang, T. Z., Xie, G. X., \& Zhu, C. (2011). Magnetic phase transitions and magnetocaloric effect in the Fe-doped MnNiGe alloys. Chin. Phys. B, 20, 097501-1-097501-4. DOI: 10.1088/16741056/20/9/097501.

6. Zhang, C. L., Wang, D. H., Cao, Q. Q, Ma, S. C., Xuan, H. C., \& Du, Y. W. (2010). Magnetic phase transitions and magnetocaloric effect in the Co-doped $\mathrm{MnNiGe}_{1.05}$ alloys. J. Phys. D: Appl. Phys., 43, 205003. DOI: 10.1088/0022-3727/43/20/205003.

7. Grandjean, F., \& Gerard, A. (1979). Mössbauer spectra of several ternary silicides, germanides and antimonides of transition metals. J. Solid State Chem., 2, 285-289.

8. Wertheim, G. K., Jaccarino, V., \& Wernick, J. H. (1964). Anisotropic hfs interactions in ferromagnets from Mössbauer effect studies. Phys. Rev., 135, A151-A154. DOI: http: //dx.doi.org/ 10.1103/ PhysRev.135.A151.

9. Fjellvag, H., \& Andersen, A. F. (1985). On the crystal structure and magnetic properties of MnNiGe. J. Magn. Magn. Mater., 50, 291-297.

10. H. Ebert Munich SPRKKR package v.6.3. DOI: http:// olymp.cup.uni-muenchen.de/.

11. Vosko, S. H., Wilk, L., \& Nusair, M. (1980). Accurate spin-dependent electron liquid correlation energies for local spin density calculations: a critical analysis. Can. J. Phys., 58, 1200-1211. DOI:10.1139/p80-159.

12. Perdew, J. P., Burke, K., \& Ernzerhof, M. (1996). Generalized gradient approximation made simple. Phys. Rev. Lett., 77, 3865-3868. DOI: http: //dx.doi. org/10.1103/PhysRevLett.77.3865. 